\title{
Pengaruh Pajak, Kepemilikan Asing dan Tunneling Incentive terhadap Penerapan Transfer Pricing pada Perusahaan Sektor Infrastruktur, Utilitas dan Transportasi di Bursa Efek Indonesia
}

\author{
Renika Hasibuan $^{1 *}$, Rolita Christina Purba ${ }^{1}$ \\ Program Studi Akuntansi, Fakultas Ekonomi dan Ilmu Sosial, Universitas Sari Mutiara \\ Jl. Kapten Muslim No. 79, Kec. Medan Helvetia, Kota Medan, Sumatera Utara \\ E-mail: *1'renikahasibuan2016@gmail.com, ${ }^{1}$ rolita.purba197ta@gmail.com
}

Received: Februari 2021; Accepted: Mei 2021; Published: Juni 2021

\begin{abstract}
The purpose of this study was to examine the effect of tax, foreign ownership and tunneling incentives on indications of transfer pricing in infrastructure, utility and transportation companies on the Indonesia stock exchange in 2014-2018. The population in this study are infrastructure, utility and transportation companies listed on the Indonesia Stock Exchange for the period in 2014-2018. The number of samples used was50 companies using purpose sampling method. The data processing program uses version 22 of the SPSS program. The analysis method used in this study is descriptive statistical test, classical assumption test, multiple linear regression, $t$ statistical test, $F$ statistical test, determination coefficient test $(R 2)$. and correlation test $(R)$. The results showed that the tax variable had no effect on the indication of transfer pricing. The foreign ownership variable has no effect on the indication of transfer pricing. The tunneling incentive variable has an effect on the indication of transfer pricing. Based on the simultaneous test (F test), the variables of tax, foreign ownership, and tunneling incentives together have an effect on indications of transfer pricing in infrastructure, utility and transportation sector companies listed on the Indonesian stock exchange in 2014-2018.
\end{abstract}

Keywords: Taxes; Foreign Ownership; Tunneling Incentive; Transfer Pricing.

\begin{abstract}
Abstrak
Tujuan penelitian ini untuk menguji pengaruh pajak, Kepemilikan Asing dan Tunneling Incentive terhadap indikasi melakukan transfer pricingpada perusahaan sektor infrastruktur, utilitas dan transportasi di Bursa Efek Indonesia tahun 2014-2018.Populasi dalam penelitian ini adalah perusahaan infrastruktur, Utilitas dan Transportasi yang terdaftar di Bursa Efek Indonesia (BEI) periode tahun 20142018. Jumlah sampel yang digunakan adalah 50 perusahaan menggunakan metode purpose sampling. Program olah data menggunakan program. Metode analisis yang digunakan dalam penelitian ini adalah uji statistik deskriftif, uji asumsi klasik, regresi linier berganda, uji statistik $t$, uji statistik $F$, uji koefisien determinasi (R2) dan uji korelasi (R).Hasil penelitian menunjukan bahwa variabel pajak tidak berpengaruh terhadap indikasi melakukan transfer pricing. Variabel kepemilikan asingtidak berpengaruh terhadap indikasi melakukan transfer pricing. Variabel tunneling incentiveberpengaruh terhadap indikasi melakukan transfer pricing. Berdasarkan uji simultan (uji F), variabel pajak, kepemilikan asing, dan tunneling incentive bersama- sama berpengaruh terhadap indikasi melakukan transfer pricing pada perusahaan sektor insfrastruktur, utilitas dan transportasi yang terdaftar di bursa efek Indonesia tahun 2014-2018.
\end{abstract}

Kata Kunci: Pajak; Kepemilikan Asing; Tunneling Incentive; Transfer Pricing.

doi: https://doi.org/10.51544/jma.v6i1.1726

(C) 2021 Jurnal Mutiara Akuntansi . This is an open access article under the CC BY-SA license

Website: http://e-journal.sari-mutiara.ac.id/index.php/JMA/

http://e-journal.sari-mutiara.ac.id 


\section{PENDAHULUAN}

Fenomena Globalisasi di dunia bisnis berdampak pada perkembangan ekonomi secara pesat keseluruh negara. Pesaing para perusahaan tidak hanya dari dalam maupun luar negeri yang menyebabkan perusahaan membuka cabang atau anak perusahaan di negara lain yang disebut dengan perusahaan multinasional. Dimana didalam perusahaan multinasional ini terjadi berbagai transaksi internasional antar divisi. Sehingga, penentu harga atas transaksi antar divisi disebut dengan transfer pricing.

Transfer pricing merupakan kebijakan perusahaan dalam harga transfer suatu transaksi finansial yang dilakukan perusahaan. Kelompok transaksi pada transfer pricing ada dua kelompok yaitu intra-company dan inter-company transfer pricing. Sebelumnya praktik transfer pricing ini dilakukan oleh perusahaan hanya untuk menilai kinerja antar divisi perusahaan. Kemudian semakin berkembangnya zaman, praktik transfer pricing juga digunakan untuk manajemen pajak yaitu dengan menekan biaya pajak dari yang sebenarnya harus dibayarkan oleh perusahaan. Ada beberapa faktor perusahaan multinasional melakukan transfer pricing, salah satunya adalah alasan pajak. Dalam perpajakan, transfer pricing telah menjadi isu klasik yang menyangkut transaksi internasional yang dilakukan oleh perusahaan multinasional. Perusahaan multinasional melakukan transfer pricing untuk memperbesar keuntungan dengan memperkecil pajak yang harus dibayarkan. Marfuah dan Azizah (2014) menyatakan bahwa pada negaranegara yang berkembang sering mengenakan tarif pajak yang lebih rendah, sedangkan negaranegara yang maju justru mengenakan tarif pajak yang tinggi. Trasfer Pricing dapat mengakibatkan berkurangnya potensi penerimaan Negara dari sektor pajak suatu Negara karena perusahaan cenderung menggeser kewajiban perpajakannya dari Negara yang memiliki tarif pajak yang tinggi ke Negara yang menerapkan tarif pajak rendah.

\section{TINJAUAN LITERATUR}

\section{Pajak}

Pajak merupakan iuran rakyat kepada kas Negara berdasarkan undang-undang (yang dapat dipaksakan) dengan tiada mendapat jasa timbal (kontraprestasi) yang langsung dapat ditunjukkan untuk membayar pengeluaran umum (Rochmat Soemitro, 2006 : 1). Pajak mempunyai peranan yang sangat penting dalam kehidupan bernegara, maka pajak mempunyai beberapa fungsi menurut Resmi (2014:3) antara lain: (1) Pajak sebagai anggaran (Budgetair) dimana dijadikan alat untuk memasukan dana ke kas negara berdasarkan UU perpajakan. (2) Pajak sebagai mengatur (Regulerend) dimana dijadikan alat untuk mencapai tujuan dan pelengkap fungsi anggaran. (3) Pajak sebagai stabilitas dimana dijadikan alat untuk membuat pemerintah memiliki dana untuk menjalankan kebijakan dengan harga, sehingga inflasi dapatdikendalikan. (4) Pajak sebagai pendapatan dimana dijadikan alat untuk membiayai semua kepentingan umum.

\section{Kepemilikan Asing}

Struktur Kepemilikan merupakan proporsi kepemilikan saham yang dimiliki oleh pihak investor, baik individual maupun institusional baik berada didalam maupun di luar perusahaan Tunneling Incentive merupakan prilaku dari pemegang saham yang mentransfer aset dan laba perusahaan demi keuntungan mereka. Transfer Pricing merupakan harga yang terkandung pada setiap produk atau jasa dari divisi 


\section{Kerangka Konseptual}

Kerangka konsep pada penelitian ini dipaparkan sebagai berikut:

\section{Hipotesis Penelitian}

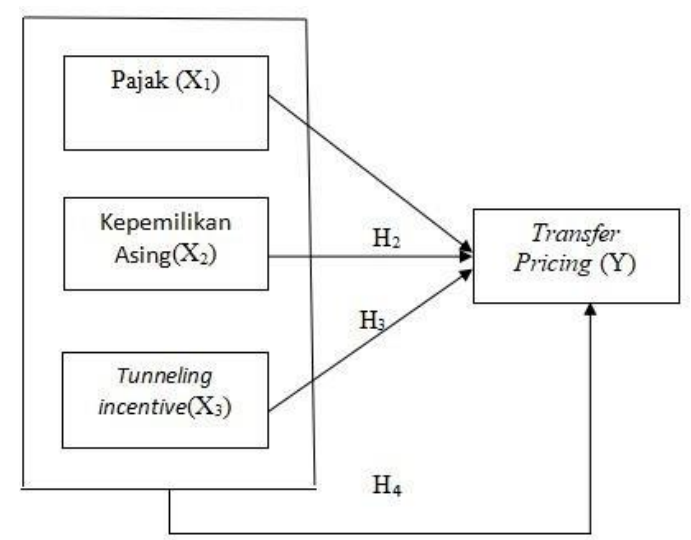

Gambar 1. Kerangka Konseptual

Adapun hipotesis pada penelitian ini adalah sebagai berikut: (1) Pajak berpengaruh terhadap keputusan transfer pricing pada perusahaan Sektor Infrastruktur, Utilitas dan Trasportasi yang terdaftar di Bursa Efek Indonesia Tahun 2014-2018. (2) Kepemilikan asing berpengaruh terhadap transfer pricing pada perusahaan Sektor Infrastruktur, Utilitas dan Trasportasi yang terdaftar di Bursa Efek Indonesia Tahun 2014-2018. (3) Tunneling incentive berpengaruh terhadap indikasimelakukan transfer pricing pada perusahaan Sektor Infrastruktur, Utilitas dan Trasportasi yang terdaftar di Bursa Efek Indonesia Tahun 2014-2018. (4) Pajak, kepemilikan asing dan Tunneling Incentive berpengaruh terhadap indikasi melakukan transfer pricing pada perusahaan Sektor Infrastruktur, Utilitas dan Trasportasi yang terdaftar di Bursa Efek Indonesia Tahun 2014-2018.

\section{METODE PENELITIAN}

\section{Jenis Penelitian}

Pada penelitian ini, jenis data yang digunakan adalah data eksplanatori dengan pendekatan kuantitaif. Dimana penelitian ini merupakan penelitian yang menelaah kauslitas antar variabel yang menjelaskkan suatu fenomena tertentu. Pada penelitian ini hubungan kausal anatar pajak, kepemilikanasing dan tunneling incentive dengan indikasi penerapan transfer pricing.

\section{Populasi dan Sampel Penelitian}

Populasi pada penelitian ini Perusahaan Jasa Sektor Infrastruktur, Utilitas dan Transportasi yang terdaftar di BEI pada tahun 2014-2018 berjumlah 79 perusahaan. Sampel pada penelitian ini menggunakan purposive sampling dengan beberapa kriteria pemilihan sampel berjumlah 10 perusahaan dikalikan 5 tahun penelitian berjumlah 50 responden.

\section{Teknik Pengumpulan Data}

Teknik pengumpulan data yang digunakan dalam penelitian ini adalah dengan menggunakan metode Riset Internet (Online Research). Teknik pengumpulan data ini dengan mengunduh data laporan keuangan tahun 2014-2018 dari situs resmi Bursa Efek Indonesia (www.idx.id) dan idn.finansial.co.id. 


\section{Operasional Variabel Penelitian}

Variabel yang digunakan dalam penelitian ini adalah variabel independen dan variabel dependen. Variabel independen terdiri dari pajak (X1), kepemilikan asing (X2), dan tunneling ncentive (X3), sedangkan variabel dependen adalah transfer pricing (Y).

\section{Metode Analisis Data}

Metode analisis data bertujuan untuk mengetahui proses pengolahan data yang dilakukan. Metode analisis data yang digunakan dalam penelitian ini adalah analisis regresi linear berganda. Pengolahan data dilakukan dengan bantuan program SPSS 22.

\section{Statistik Deskriptif}

Statistik deskriptif ini menggambarkan tentang data masing-masing variabel yang terdiri dari nilai minimum, maksimum, rata-rata, dan standar deviasi. Data yang diteliti dalam analisis statistik deskriptif adalah, pajak, kepemilikan asing dan tunneling incentive dan transfer pricing

\section{Uji Asumsi Klasik}

Untuk memperoleh hasil pengujian yang baik maka data harus diuji terlebih dahulu agar tidak melanggar asumsi klasik, sehingga memperoleh hasil pengujian hipotesis yang tepat dan dapat dipertanggungjawabkan serta menghasilkan model regresi yang signifikan dan representatif. Uji asumsi klasik terdiri dari Uji Normalitas, Uji Multikolinieritas, Uji Heteroskedastisitas, Uji Autokorelasi

\section{Pengujian Hipotesis}

Pengujian hipotesis dalam penelitian ini menggunakan metode analisis regresi linear berganda dengan rumus sebagai berikut :

$\mathrm{Y}=\alpha+\mathrm{b} 1 \mathrm{X} 1+\mathrm{b} 2 \mathrm{X} 2+\mathrm{b} 3 \mathrm{X} 3+\varepsilon$

Keterangan :

$\mathrm{Y}=$ Transfer Pricing

$\mathrm{A}=$ Konstanta

$\mathrm{B}=$ Koefisien Regresi

$\mathrm{X} 1$ = Pajak

$\mathrm{X} 2$ = Kepemilikan Asing

$\mathrm{X} 3$ = Tunneling Incentive

$\varepsilon=$ Error

Pengolahan data dilakukan dengan bantuan program SPSS 22.

Pengujian hipotesis dalam penelitian ini menggunakan pengujian t-statistik, pengujian Fstatistik dan koefisien Determinasi (R2).

\section{Koefisien Korelasi $(R)$ dan Determinasi $(R 2)$}

Koefisien korelasi $(\mathrm{R})$ bertujuan untuk menguji apakah dua variabel yaitu variabel bebas dan variabel terikat mempunyai hubungan yang kuat atau tidak kuat atau apakah hubungan tersebut positif atau negatif (Sugiyono, $2014: 241$ ).

\section{Uji Statistik F (Secara Simultan)}

Pengujian ini bertujuan untuk melihat model regresi apakah variabel independen secara bersama-sama berpengaruh terhadap variabel dependen. Dasar pengambilan keputusan uji $\mathrm{F}$ yaitu perbandingan nilai Fhitung dengan Ftabel. 
1. Jika Jika $F_{\text {hitung }}>F_{\text {tabel }}$, maka hipotesis diterima, berarti ada pengaruh yang signifikan antara variabel indpenden $(\mathrm{X})$ secara bersama-sama terhadap variabel $(\mathrm{Y})$.

2. Jika $F_{\text {hitung }}<F_{\text {tabel, }}$ maka hipotesis ditolak, berarti tidak ada pengaruh yang signifikan antara variabel independen secara bersama-sama terhadap variabel (Y).

\section{Uji Statistik t (Secara Parsial)}

Pengujian ini bertujuan untuk mengetahui seberapa jauh suatu variabel independen secara individual dalam menerangkan variasi variabel dependen. Pengujian ini dilakukan dengan berdasarkan nilai signifikan dan berdasarkan perbandingan nilai thitung dengan ttabel. Berdasarkan nilai signifikan (sig) :

1. Jika thitung $>t_{\text {tabel}}$, maka ada pengaruh variabel bebas $(\mathrm{X})$ terhadap variabel terikat $(\mathrm{Y})$ atau hipotesis diterima.

2. Jika thitung $<t_{\text {tabel}}$, maka tidak ada pengaruh variabel bebas $(X)$ terhadap variabel terikat $(Y)$ atau hipotesis ditolak.

\section{HASIL DAN PEMBAHASAN}

Sebelum mengetahui bagaimana pengaruh pajak, kepemilikan asing dan tunneling incentive terhadap penerapan transfer pricing pada perusahaan sektor infrastruktur, utilitas dan transportasi, terlebih dahulu melakukan pengujian data apakah data tersebut normal atau tidak. Alat ukur untuk penormalan data menggunakan uji asumsi klasik dengan menggunakan tiga metode antara lain: Uji asumsi klasik menggunakan grafik P-Plot dengan hasil titik menyebar disekitar garis diagonal yang berasumsi data berdistribusi normal. Metode kedua menggunakan uji multikolinearitas dengan melihat nilai VIF kurang dari atau $<10$ dan nilai toleransi lebih besar atau > 0,1 yang berasumsi data tidak terjadi multikolinearitas. Dan yang metode ketiga menggunakan uji heteroskedastisitas dengan hasil bahwa data menyebar secara merata diatas dan dibawah nol dan tidak berkumpul pada satu tempat dengan asumsi tidak terjadi heterokedastisitas.

Uji Koefisien Determinasi $\left(R^{2}\right)$

Uji Koefisien Determinasi $\left(\mathrm{R}^{2}\right)$ dam korelasi dapat dilihat pada tabel berikut ini:

Tabel 1

Hasil Uji Koefisien Determinasi $\left(\mathrm{R}^{2}\right)$ dan Korelasi

\begin{tabular}{lcccc}
\hline Model & $\mathrm{R}$ & $\mathrm{R}$ Square & Adjusted R Square & Std. Error of the Estimate \\
\hline 1 & $.424^{\mathrm{a}}$ & .179 & .126 & .246363 \\
\hline
\end{tabular}

a. Predictors: (Constant), Tunneling Incentive, Pajak, Kepemilikan Asing

b. Dependent Variable: Transfer Pricing

Sumber: Hasil Output SPSS.

Berdasarkan Tabel 1 diatas, Koefisien korelasi menunjukkan angka $\mathrm{R}$ sebesar 0,424 yang menunjukkan bahwa nilai $\mathrm{R}$ berada di interval korelasi 0,40-0,599 pada tingkat hubungan sedang.

koefisien determinasi R2 menunjukkan angka R Squaresebesar 0,179 atau 17,9\% yakni variasi variabel transfer pricing dapat dijelaskan oleh pajak, Kepemilikan Asing dan Tunneling Incentive,sisanya $82,1 \%$ dapat dipengaruhi oleh faktor lain diluar variabel penelitian. 


\section{Uji Statistik F (Secara Simultan)}

Hasil uji-F dapat dilihat pada tabel 2 berikut ini :

\begin{tabular}{|c|c|c|c|c|c|c|}
\hline \multicolumn{7}{|c|}{$\begin{array}{c}\text { Tabel } 2 \\
\text { Hasil Uii F }\end{array}$} \\
\hline & & Sum of Squares & $\mathrm{df}$ & Mean Square & F & Sig. \\
\hline \multirow[t]{3}{*}{1} & Regression & .610 & 3 & .203 & 3.351 & $.027^{\mathrm{a}}$ \\
\hline & Residual & 2.792 & 46 & .061 & & \\
\hline & Total & 3.402 & 49 & & & \\
\hline
\end{tabular}

a. Predictors: (Constant), Tunneling Incentive, Pajak, Kepemilikan Asing

b. Dependent Variable: Transfer Pricing

Untuk menentukan koordinat $\mathrm{F}_{\text {tabel }}$ dapat digunakan rumus koordinat $\mathrm{F}_{\text {tabel }}=\mathrm{n}-1: \mathrm{fk}-\mathrm{n}=$ 3-1 ; 50-3 = 2 ; 47 maka, Pengambilan keputusan dengan menggunkan uji F sebagai berikut :

1. Ho : $F_{\text {hitung }}<F_{\text {tabel }}$ : berarti tidak ada pengaruh yang signifikan dari pajak, kepemilikan asing dan tunneling incentive terhadap transfer pricing.

2. $\mathrm{H} 4: \mathrm{F}_{\text {hitung }}>_{\text {tabel }}$ : berarti ada pengaruh yang signifikan dari pajak, kepemilikan asing dan tunneling incentive terhadap transfer pricing.

3. Hasil perhitungan statistik menunjukkan nilai $F_{\text {hitung }}$ sebesar 3,351 dengan nilai $F_{\text {tabel }}=3,20$ dan nilai signifikansi sebesar 0,27. Hal ini berarti bahwa secara bersama-sama Pajak, kepemilikan Asing dan Tunneling Incentive mempunyai pengaruh secara bersama - sama terhadap Transfer Pricing atau H4 diterima.

Uji Statistik t (Secara Parsial)

Hasil uji-t dapat dilihat pada tabel 3 berikut ini:

Tabel 3. Hasil Uji t

\begin{tabular}{|c|c|c|c|c|c|c|}
\hline \multicolumn{2}{|c|}{ Model } & \multicolumn{2}{|c|}{ Unstandardized Coefficients } & \multirow{2}{*}{$\begin{array}{c}\text { Standardized Coefficients } \\
\text { Beta }\end{array}$} & \multirow[t]{2}{*}{$\mathrm{T}$} & \multirow[t]{2}{*}{ Sig. } \\
\hline \multirow{5}{*}{1} & & $\mathrm{~B}$ & Std. Error & & & \\
\hline & (Constant) & .003 & .074 & & .043 & .966 \\
\hline & Pajak & -.014 & .021 & -.091 & -.656 & .515 \\
\hline & Kepemilikan Asing & .121 & .139 & .123 & .867 & .391 \\
\hline & Tunneling Incentive & .264 & .099 & .370 & 2.675 & .010 \\
\hline
\end{tabular}

Sumber: Hasil OutputSPSS. 22.

Dari hasil tersebut diatas, apabila ditulis dalam bentuk persamaan regresinya adalah sebagai berikut.

$\mathrm{Y}=0,003-0,014 \mathrm{X}_{1}+0,121 \mathrm{X}_{2}+0,264 \mathrm{X} 3+\varepsilon$

Keterangan :

$\mathrm{Y}=$ Transfer Pricing

$\mathrm{A}=$ Konstanta

$\mathrm{B}=$ Koefisien Regresi

$\mathrm{X} 1$ = Pajak

$\mathrm{X} 2$ = Kepemilikan Asing

$\mathrm{X} 3$ = Tunneling Incentive

$\varepsilon \quad=$ Error

Persamaan analisis regresi linear berganda ini dapat diartikan sebagai berikut:

1. Nilai konstanta 0,003 , artinya jika $X 1, X 2$, dan $\mathrm{X} 3=0$, maka $\mathrm{Y}=0,003$

2. Nilai koefisien regresi Pajak $\left(X_{1}\right)$ sebesar $-0,014$, artinya jika Pajak naik satu satuan dan variabel lainnya tetap maka Pajak Penghasilan akan naik sebesar -0,014. 
3. Nilai koefisien regresi Kepemilikan Asing $\left(\mathrm{X}_{2}\right)$ sebesar 0,121 artinya jika Kepemilikan Asing naik satu satuan dan variabel lainnya tetap maka Transfer Pricing akan naik sebesar 0,121.

4. Nilai koefisien regresi Tunneling Incentive (X3) sebesar 0,264artinya jika Tunneling Incentive naik satu satuan dan variabel lainnya tetap maka Transfer Pricing naik sebesar 0,264 .

Dari tabel di atas terlebih dahulu mencari nilai $t_{\text {hitung }}$ pada tabel 2 kemudian mencari nilai $\mathrm{t}_{\text {tabel }}$ pada tabel uji-t yang ada pada lampiran. Untuk menentukan koordinat $\mathrm{t}_{\text {tabel }}=0,05 ;(50-3-1)$ $=0,05 ;(46)$. Berdasarkan tabel 2 dapat disimpulkan sebagai berikut :

1. Diketahui bahwa variabel Pajak memiliki $t_{\text {hitung }}$ sebesar $-0,656$ sedangkan $t_{\text {tabel }}$ Sebesar 2,01290 sehingga $-0,656<2,01290$ dengan probabilitas signifikan sebesar 0,515>0,05 maka $\mathrm{H}_{1}$ ditolak yang artinya bahwa secara parsial pajak tidak berpengaruh terhadap indikasi melakukan transfer pricing pada perusahaan Sektor Infrastruktur, Utilitas dan Trasportasi yang terdaftar di BEI tahun 2014-2018.

2. Kepemilikan Asing $t_{\text {hitung }}$ sebesar 0,867 sedangkan $t_{\text {tabel }} 2,01290$ sehingga $-0,867<2,01290$ dengan probabilitas sebesar 0,391>0,05 maka $\mathrm{H}_{2}$ ditolak sehingga dapat disimpulkan bahwa secara parsial Kepemilikan Asing tidak berpengaruh terhadap indikasi melakukan transfer pricing pada perusahaan Sektor Infrastruktur, Utilitas dan Trasfortasi yang terdaftar di BEI tahun 2014-2018.

3. Tunneling Incentive memiliki $t_{\text {hitung }}$ sebesar 2,675 sedangkan $t_{\text {tabel }} 2,01290$ sehingga 2,675 > 2,01290 dengan probabilitas signifikan sebesar 0,010>0,05 maka $\mathrm{H}_{3}$ diterima sehingga dapat disimpulkan bahwa secara parsial Tunneling Incentive berpengaruh terhadap indikasi melakukan transfer pricing pada perusahaan Sektor Infrastruktur, Utilitas dan Trasfortasi yang terdaftar di BEI tahun 2014-2018.

\section{Pengaruh Pajak terhadap Transfer Pricing}

Hasil Hipotesis 1 (satu) menyatakan bahwa pajak berpengaruh terhadap indikasi melakukan transfer pricing. Hasil penelitian menunjukkan pajak tidak berpengaruh terhadap indikasi melakukan transfer pricing sesuai dengan hasil hipotesis dengan menggunakan uji t. Hal ini menunjukkan tidak terdapat pengaruh terhadap transfer pricing sehingga $\mathrm{H}_{1}$ ditolak.

\section{Pengaruh Kepemilikan Asing terhadap Transfer Pricing}

Hasil Hipotesis 2 (dua) menyatakan bahwa Kepemilikan Asing berpengaruh signifikan terhadap indikasi melakukan transfer pricing. Hasil penelitian menunjukkan Kepemilikan Asing tidak berpengaruh terhadap indikasi melakukan transfer pricing sesuai dengan hasil hipotesis dengan menggunakan uji t. Hal ini menunjukkan tidakterdapat pengaruh terhadap indikasi melakukan transfer pricing sehingga $\mathrm{H}_{2}$ ditolak.

\section{Pengaruh Tunneling Incentive terhadap Transfer Pricing}

Hasil Hipotesis 3 (tiga) menyatakan bahwa Tunneling Incentive berpengaruh terhadap indikasi melakukan transfer pricing. Hasil penelitian menunjukkan ada pengaruh terhadap transfer pricing sesuai dengan hasil hipotesis dengan menggunakan uji t. Hal ini menunjukkan tidak ada pengaruh terhadap transfer pricing sehingga $\mathrm{H}_{3}$ diterima.

\section{Pengaruh Pajak, Kepemilikan Asing, Tunneling Incentive terhadap Transfer Pricing}

Berdasarkan hasil uji f atau uji simultan pada tabel 4.6dapat dilihat bahwaFhitung sebesar 3,351 dengan nilai Ftabel = 3,20 dan nilai signifikansi sebesar 0,27. Hal ini berarti bahwa secara 
bersama-sama Pajak, kepemilikan Asing dan Tunneling Incentive mempunyai pengaruh secara bersama - sama atau simultan berpengaruh terhadap transfer pricing pada perusahaan Sektor Infrastruktur, Utilitas dan Trasportasi yang terdaftar di BEI tahun 2014-2018.

\section{KESIMPULAN}

Berdasarkan hasil peneletian dan kajian yang telah diuraikan sebelumnya, maka dapat disimpulkan menjadi beberapa hal sebagai berikut :

1. Variabel pajak $\left(\mathrm{X}_{1}\right)$ tidak berpengaruh terhadap indikasi melakukan transfer pricing pada perusahaan sektor Infrastruktur, utilitas dan transportasi di BEI tahun 2014-2018.

2. Variabel kepemilikan asing $\left(\mathrm{X}_{2}\right)$ tidak berpengaruh terhadap indikasi melakukan transfer pricing pada perusahaan sektor Infrastruktur, utilitas dan transportasi di BEI tahun 2014-2018.

3. Variabel tunneling incentive (X3) berpengaruh terhadap indikasi transfer pricing pada perusahaan sektor Infrastruktur, utilitas dan transportasi di BEI tahun 2014-2018.

Penelitian ini menguji Pengaruh Price Earning Ratio, Debt to Equity Ratio dan Return On Asset terhadap Harga Saham pada perusahaan makanan dan minuman yang terdaftar di Bursa Efek Indonesia. Maka dapat disimpulkan pengaruh variabel-variabel independen terhadap harga saham adalah sebagai berikut.

1. Berdasarkan pengujian secara parsial, Price Earning Ratio (PER) tidak berpengaruh signifikan terhadap harga saham pada perusahaan makanan dan minuman yang terdaftar di BEI karena Price Earning Ratio tidak dapat memberikan informasi yang mutlak dalam memprediksi harga saham pada perusahaan manufaktur sub sektor makanan dan minuman .

2. Berdasarkan pengujian secara parsial, Debt to Equity Ratio (DER), tidak berpengaruh signifikan terhadap harga saham pada perusahaan makanan dan minuman yang terdaftar di BEI karena Debt to Equity Ratio tidak dapat memberikan informasi yang mutlak dalam memprediksi harga saham pada perusahaan makanan dan minuman .

3. Berdasarkan pengujian secara parsial, Return On Asset, berpengaruh signifikan positif terhadap harga saham pada perusahaan makanan dan minuman yang terdaftar di BEI. Hal ini berarti variabel ini dapat memberikan informasi dalam memprediksi harga saham.

4. Berdasarkan pengujian secara simultan, Price Earning Ratio, Debt to Equity Ratio dan Return On Asset berpengaruh terhadap harga saham pada perusahaan makanan dan minuman yang terdaftar di BEI. Hal ini berarti vaeriabel Price Earning Ratio, Debt to Equity Ratio dan Return On Asset secara bersamaan dapat memberikan informasi dalam memprediksi harga saham pada perusahaan makanan dan minuman.

Berdasarkan kesimpulan yang diuraikan di atas, maka disarankan :

1. Bagi Akademik hasil penelitian ini dapat digunakan sebagai bahan literatur dan referensi dalam melakukan penelitian selanjutnya terkait analisis praktik transfer pricing terhadap pajak, kepemilikan asing dan tunneling incentive.

2. Bagi investor sebaiknya untuk menanamkan sahamnya di perusahaan sektor infrastruktur, utilitas dan transportasi yang terdaftar di Bursa Efek Indonesia agar lebih seksama dan juga memperhatikan aspek Pajak, Kepemilikan Asing dan Tunneling Incentive sebagai pertimbangan dalam melakukan investasi.

3. Bagi peneliti selanjutnya yang ingin meneliti dengan topik yang sama agar dapat menambahkan variabel lain dan juga objek yang lebih luas yang mungkin dapat mempengaruhi tindakan transfer pricing perusahaan perdagangan, jasa \& investasi yang terdaftar di Bursa Efek Indonesia (BEI). 


\section{DAFTAR PUSTAKA}

Aharony, et al., 2010. Tunneling Incentive as an incentive for earnings management during the IPO process in China. Journal of Accounting and Public Policy. 29 (1), 1-26.

Atmaja, Lukas Setia, 2011, Who Wants To Be Rational Investor, Kepustakaan Populer Gramedia. Jakarta.

Dyreng, Scott D, et al,. 2010. The Effect of Executives on Corporate Tax Avoidance. The Accounting Review, 85(4), 1163-1189.

Frank, M, et al. 2008. Tax Reporting Aggressiveness and its Relation to Aggressive Financial Reforting. Accounting Review, 84(2), 467-496

Gusnardi, I. 2009. Penetapan Harga Trasfer Dalam Kajian Perpajakan. Pekbis Jurnal, 1(1), 36-43

Ghozali .2006. Aplikasi analisis Multivariate dengan Program SPSS (Edisi ke 4). Semarang: Badan Penerbit Universitas Diponegoro.

Hartati, Winda, dkk. 2014. Analisis Pengaruh Pajak dan Mekanisme Bonus Terhadap Keputusan Transfer Pricing: Studi Empiris Pada Seluruh Perusahaan yang Listing di Bursa Efek Indonesia. Jurnal SNA Mataram.

Lo, Agnes W. Y.., et al, 2010. Tax, Financial Reporting, and Tunneling Incentives for Income Shifting: An Empirical Analysis of the Transfer Pricing Behavior of Chinese-Listed Companies. Journal of the American Taxation Association, 32(2), 1-26.

Mangonting. 2000. Aspek Perpajakan Dalam Transfer Pricing, Jurnal Akuntansi \& Keuangan, 2(1), 69-82

Mardiasmo. 2008. Perpajakan (edisi Revisi 2008). Yogyakarta: Andi Offset.

Marfuah dan APN. Azizah (2014), Pengaruh Pajak, Tunneling Incentive, dan Exchange Rate pada Keputusan Transfer Pricing. Jurnal Akuntansi dan investasi, Vol 16No 1.

Mispiyanti (2015), Pengaruh Pajak, Tunneling Incentive dan Mekanisme BonusTerhadap Keputusan Transfer Pricing. Dalam Jurnal Akuntansi dan Investasi, 16(1), 62-74.

Resmi, Siti. 2014. Perpajakan Teori dan Kasus, Buku 1 edisi 8. Salemba Empat. Jakarta.

Sugiyono (2012), Statistik Untuk Penelitian, Alfabeta, Bandung. Sukardji,

Saifudin, dkk. 2018. Determinasi Pajak, Mekanisme Bonus, Dan Tunnelling Incentive terhadap Keputusan Transfer Pricing PadaPerusahaanManufakturyang Listing di Bursa Efek Indonesia. Jurnal ekonomi dan bisnis, 2(1), 32-43

Suandy, Erly. 2011. Perencanaan pajak. Edisi Kelima. Jakarta: Salemba Empat.

Soemitro, Rochmat, 2006, Dasar-Dasar Hukum Pendapatan , Jakarta : Salemba Empat.

Sugiyono. 2014. Metode Penelitian Pendidikan Pendekatan Kuantitatif, Kualitatif.

Undang-undang No. 16 Tahun 2009 Pasal 1 : Ketentuan Umum dan Tata Cara Perpajakan. Http://kemenkeu.go.id.

Undang-undang No. 17 tahun 2000 Pasal 1 : Pajak Penghasilan. Http://kemenkeu. 
go.id.

Undang-Undang Republik Indonesia No. 25 Tahun 2007 tentang Penanaman Modal

Undang-undang No. 28 Tahun 2007 Pasal 1 :Ketentuan Umum Perpajakan (KUP)

Http://kemenkeu.go.id.

Undang-undang No. 36 Tahun 2008.Tentang Pajak Penghasilan.

Wang, Y., \& Ruhe, G. R. (2007). The Cognitive Process of Decision Making. International Journal of Cognitive Informatics and Natural Intelligence, 1(2), 73-85.

Wafiroh, Novi Lailiyul., dan Niken Nindya Hapsari. 2015. "Pajak, Tunneling Incentive dan Mekanisme Bonus pada Keputusan Transfer Pricing.” El-Muhasaba 6(2):157-168. 